\title{
Effect of Radiofrequency Radiation from Telecommunication Base Stations on Microbial Diversity and Antibiotic Resistance
}

\author{
E.A, ADEBAYO ${ }^{1}$; A.O, ADEEYO ${ }^{* 1}$; A.A, AYANDELE ${ }^{1}$ I.O, OMOMOWO ${ }^{1}$ \\ 1 Department of Pure and Applied Biology, Ladoke Akintola University of Technology, P.M.B. 4000, Ogbomoso, Nigeria \\ eaadebayo@lautech.edu.ng; firstrebby@gmail.com,lizdeley@yahoo.com and olaiyabo@yahoo.com \\ Corresponding author: A.O ADEEYO. E-Mail: firstrebby@gmail.com
}

\begin{abstract}
We aimed to investigate the effects of radiofrequency radiation from telecommunication on bacteria diversity and antibiotic sensitivity of surrounding bacteria micro-flora. In all cases of bacteria isolated, results indicated that radiation majorly influences and selected bacteria of specific morphology (rod-like, gram positive and spore formers) belonging to the genera Bacillus, Clostridium, Corynebacterium and Sporosarcina. Spore formation have been associated with prevention of DNA damage, this suggest that radiation may imposes stress detrimental to various non-spore forming, gram negative bacteria of nonrod morphology. The antibiotic resistance pattern indicated resistance above $50 \%$ in three of the ten common antibiotics tested with the highest of $96 \%$ recorded against zinnacef, followed by amoxicillin $(70 \%)$ and ampiclox $(56 \%)$. The highest resistance recorded was attributed to Bacillus spp while lowest resistance was recorded in Corynebacterium. The two largest groups of isolates; Bacillus and Clostridium have been reported as human pathogens and found to be multidrug resistant. (C JASEM
\end{abstract}

http://dx.doi.org/10.4314/jasem.v18i4.16

\section{Introduction:}

Before the 1990's radiofrequencies were mainly from a few radio and television transmitters, located in remote areas and/or very high places. Since the introduction of wireless telecommunication in the 1990's the rollout of phone networks has caused a massive increase in electromagnetic pollution in cities and the countryside (Firstenberg, 1997; Galeev, 2000). Multiple sources of mobile communication result in chronic exposure of a significant part of life (and man) to microwaves at non-thermal levels (Belyaev, 2005). In recent years, life has been chronically exposed to microwaves and RFR (Radiofrequency radiation) signals from various sources, including Global system for mobile communication (GSM) and UMTS/3G wireless phones and base stations, Wireless Local Area Networks (WLAN), Wireless Personal Area Networks such as Bluetooth (WPAN), and DECT (Digital Enhanced (former European) Cordless Telecommunications) that are erected indiscriminately without studies of environmental impact assessments.

The effects of RFR on the biological functions of living organisms represent an emerging area of interest with respect to environmental influences on human health. In latest years, several studies have been performed to verify direct effects exerted by such radiations on cell functions. Although results have been somewhat controversial, a variety of cell responses have been observed involving proliferation and differentiation (Huang et al., 2006; Lisi et al., 2006; Lisi et al., 2008; Vianale et al., 2008; Schwartz et al., 2008; Foleti et al., 2009), gene expression (Piacentini et al., 2008; Goodman et al., 2009), modulation of the membrane receptors functionality (Jia et al., 2007; Ke at al., 2008; De-Mattei et al., 2009), apoptosis, alteration in ion homeostasis (Grassi et al., 2004; Lisi et al., 2006; Iorio et al., 2011 ), and free radicals generation (Simk, 2007; DiLoreto et al., 2009). Bacteria have also been used in the studies with radiofrequency radiation (Stra`s'ak, et al., 2005; Fojt et al., 2004; Babushkina et al., 2005; Justo et al., 2006; Gaafar et al., 2006; Cellini et al., 2008; Gaafar et al., 2008; Fojt., 2009; Belyaev, 2011; Inhan-Garip et al., 2011, Giorgi et al., 2011). In particular, it has been demonstrated that radiation can negatively (Stra's'ak, et al., 2005; Fojt et al., 2004; Justo et al., 2006) or positively (Gaafar et al., 2006; Cellini et al., 2008; Belyaev, 2011) affect functional parameters (cell growth and viability) and bacteria antibiotic sensitivity depending on physical parameters of the electromagnetic field (frequency and magnetic flux density) applied, the time of the exposure, and/or the type of bacteria cells used. The possibility of an effect evoked by RFR on bacterial distribution and antibiotic resistance deserves special 
attention in light of the risk that antimicrobial resistance poses to public health. Bacteria are becoming increasingly resistant to almost all presently available antibiotics and this aspect is becoming a worldwide problem of highest significance (Levi, 2001; Bush et al., 2011). According to these considerations, the study of effects of RFR on bacteria is essential not only for investigation of environmental stress influences on biological systems, but also to explore the antibiotic resistance pattern associated for possibility of controlling bacteria in the environment or in clinical laboratories. We have therefore attempted to investigate the possible influence of RFR on bacteria distribution and antibiotic resistance on surrounding bacteria micro-flora of telecommunication base stations located around Ladoke Akintola University of Technology, Ogbomoso, Oyo State, Nigeria.

\section{MATERIALS AND METHODS}

Sample collection: Soil samples were collected from telecommunication base station located around Ladoke Akintola University of Technology, Ogbomoso, Oyo State, Nigeria. These were collected between 0 and $100 \mathrm{ft}(0,10,40,70$ and 100ft) from the foot of 3 base stations. Soil samples were aseptically transferred to the laboratory for microbial analysis.

Isolation of organisms: $1 \mathrm{~g}$ of each soil samples was weighed into $10 \mathrm{ml}$ of sterile distilled water. Subsequent transfer of $1 \mathrm{ml}$ into $9 \mathrm{ml}$ of sterile distilled water was engaged for serial dilution of the prepared samples followed by plating out on nutrient agar using pour plate techniques. The cultures were incubated at $37^{\circ} \mathrm{C}$ for $24 \mathrm{~h}$ from where pure cultures were prepared based on bacteria morphology using the streaking out method.

Biochemical characterization and identification of pure cultures: Pure bacterial cultures were identified on the basis of grams reaction, morphology and biochemical reactions including sugar hydrolysis, catalase, oxidase, urease, indole, citrate utilization, methyl red, nitrate reduction and voges proskaeur tests. The organisms isolated were then characterized according to the taxonomic scheme of Buchanan and Gibbons (1974).

Antibiotic susceptibility tests: Susceptibility of purified bacterial cultures to a set of ten antimicrobial substances was assessed by disk diffusion on Mueller-Hinton agar plates according to the Clinical and Laboratory Standards Institute guidelines (CLSI, 2007). After incubation, for $24 \mathrm{~h}$ at $37^{\circ} \mathrm{C}$, the sizes of zones of inhibitions were measured and interpreted by comparing with the standard antibiotic sensitivity chart to determine their resistant patterns. Resistance was calculated according to the method of Adebayo et al. (2012).

Antimicrobial agents: Antibiotics used include Pefloxacin (PEF), Gentamycin (CN), Ampiclox (APX), Zinnacef (Z), Amoxicillin (AM), Rocephin (R), Ciprofloxacin (CPX), Streptomycin (S), Septrin (SXT), and Erythromycin (E) and were purchased through Labtrade Chemicals, Nigeria.

\section{RESULTS AND DISCUSSION:}

The result of microbial diversity and prevalence around telecommunication base stations studied is indicated in Table 1. A total of 27 bacteria isolates belonging to four genera were identified. Result show a high occurrence of Bacillus spp (78 \%), followed by Clostridium spp (11\%), Corynebacterium striatum (7\%) and Sporosarcina ureae (4\%) with the lowest distribution. Result indicated that RFR majorly influences and selected bacteria of specific morphology (rod-like, gram positive and spore formers) around the three telecommunication base stations sampled. Radiation effect seems to favour majorly the growth of Bacillus spp between the distance of 0 and $100 \mathrm{ft}$ with occasional presence of Corynebacterium striatum, Sporosarcina ureae and Clostridium tertium at 10 , and $70 \mathrm{ft}$ from the base station. Spore formation has been associated with prevention of DNA damage and this suggests that radiation may impose stress detrimental to various non-spore forming, gram negative bacteria of non-rod shape. The presence of limited genera which are mostly spore formers showed that these groups survived because of their ability to form spores which protected them from the negative effect of radiation while others are probably eliminated. Rifat et al. (2010) reported Rhizobium, Bradyrhizobium, Azorhizobium, Allorhizobium, Sinorhizobium, Mesorhizobium, Azospirillum, Enterobacter, Klebsiella, and Pseudomonas spp as symbiotic and free living beneficial groups of bacteria commonly encountered in the soil and have potential to contribute to sustainable plant growth. However none of these were isolated. The depletion of such nitrogen fixing bacteria will likely lead to soil infertility as such organism cannot protect themselves from the effect of radiation. This may invariably lead to reduction in yield and productivity of food crops in such environment. Previous report have implicated the ability of radiation to induce changes of cell growth and antibiotic sensitivity in bacteria strains (Grossman et al., 1992; Stansell et al., 2001; 
Table 1: Diversity and prevalence of bacteria isolates from Telecommunication base stations in LAUTECH.

\begin{tabular}{lllll}
\hline Isolates & Prevalence & Gram reaction & Shape & Spore formation \\
\hline Bacillus spp & $21(78 \%)$ & Positive & Rods & Spore formers \\
Clostridium spp & $3(11 \%)$ & Positive & Rods & Spore formers \\
Corynebacterium striatum & $2(7 \%)$ & Positive & Rods & $\begin{array}{l}\text { Non-Spore } \\
\text { formers }\end{array}$ \\
Sporosarcina ureae & $1(3 \%)$ & Positive & cocci & Spore formers
\end{tabular}

Fojt et al., 2004; Justo et al., 2006; Fojt et al., 2007; Fojt et al., 2009). It has been found that viability of different types of bacteria (Escherichia coli, Leclercia adecarboxylata, and Staphylococcus aureus) was affected after exposure to an RFR (Fojt et al., 2004). RFR have been reported to be lethal in Paracoccus denitrificans, but without changes in denitrification activity (Fojt et al., 2009). While RFR as reported in this work is attributed to influencing the presence of majorly rod-shaped bacteria, Fojt et al. (2008) do not observe any change in bacterial morphology after short period of exposure to RFR suggesting that the radiation selected and caused survival of bacteria with specific shape and adaptive feature in the environment rather than causing a shape change in such organism. On the contrary, it has been demonstrated that short-term exposure RFR with a sinusoidal waveform of amplitude ranging from 0.1 to $1 \mathrm{mT}$ and frequency of $50 \mathrm{~Hz}$ affected morphology of cultured E. coli ATCC 700926 (Cellini et al., 2008).
The antibiotic resistant patterns of various bacteria isolated are indicated In Table 2 and Figure 1. Antibiotic resistance among the radiofrequency radiation resistant bacteria indicated that resistance was above $50 \%$ in three of the ten common antibiotics tested. Among the twenty seven isolates, $26(96 \%)$ were resistant to zinnacef, $19(70 \%)$ to amoxicillin, $15(56 \%)$ to ampiclox, $5(19 \%)$ to pefloxacin and gentamycin respectively, $3(11 \%)$ to erythromycin, $2(7 \%)$ to rocephin and septrin and 1 $(4 \%)$ to streptomycin and ciprofloxacin. With respect to the ten antibiotics used, Bacillus spp has resistance to all (100\%) antibiotics used, Clostridium spp was resistant to four $(40 \%)$ while Corynebacterium striatum and Sporosarcina ureae were resistant to two (20\% resistant) each, among the ten antibiotic used. Highest resistance was recorded in Bacillus spp while lowest resistance was recorded in Corynebacterium. The two largest groups of isolates of Bacillus and Clostridium have been reported as human pathogens and found to be multidrug resistant (Conner-kerr et al., 1998). Bacillus circulans and Clostridium septicum have been

Table 2: Antibiotic resistant pattern in radiofrequency radiation resistant bacteria Isolated from LAUTECH.

\begin{tabular}{|c|c|c|c|c|c|c|c|c|c|c|c|}
\hline Isolates & & Antibio & with pro & prtion and & rcentage l & cteria resi & ance & & & & \\
\hline & Number & PEF & CN & APX & $\mathbf{Z}$ & $\mathbf{A M}$ & $\mathbf{R}$ & CPX & $\mathbf{S}$ & SXT & $\mathbf{E}$ \\
\hline Bacillus spp & 21 & 5 & 4 & 11 & 20 & 16 & 2 & 1 & 1 & 2 & 3 \\
\hline Clostridium spp & 3 & 0 & 1 & 1 & 3 & 2 & 0 & 0 & 0 & 0 & 0 \\
\hline $\begin{array}{l}\text { Corynebacterium } \\
\text { striatum }\end{array}$ & 2 & 0 & 0 & 2 & 2 & 0 & 0 & 0 & 0 & 0 & 0 \\
\hline Sporosarcina ureae & 1 & 0 & 0 & 1 & 1 & 1 & 0 & 0 & 0 & 0 & 0 \\
\hline Total & 27 & $5(19 \%)$ & $5(19 \%)$ & $15(56 \%)$ & $26(96 \%)$ & $19(70 \%)$ & $2(7 \%)$ & $1(4 \%)$ & $1(4 \%)$ & $2(7 \%)$ & $3(11 \%)$ \\
\hline
\end{tabular}

Pefloxacin (PEF), Gentamycin (CN), Ampiclox (APX), Zinnacef (Z), Amoxicillin (AM), Rocephin (R), Ciprofloxacin (CPX), Streptomycin (S), Septrin (SXT), and Erythromycin (E) 


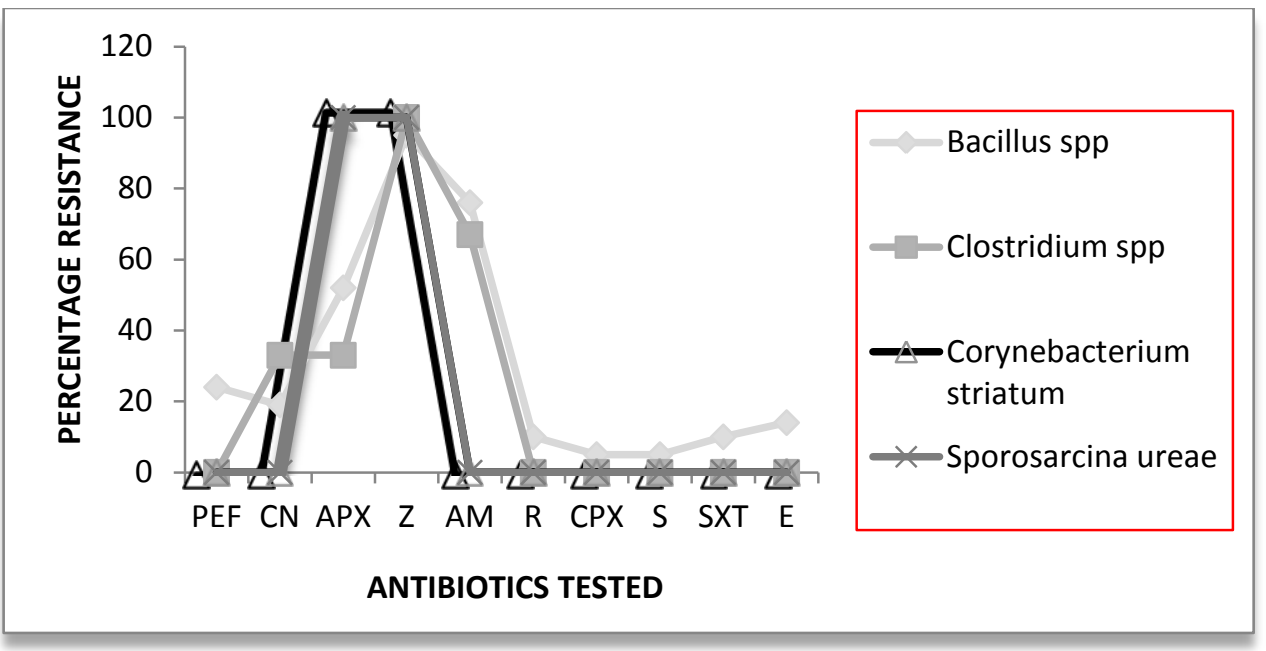

Fig 1: Percentage resistance to antibiotics among bacteria strains isolated

Pefloxacin (PEF), Gentamycin (CN), Ampiclox (APX), Zinnacef (Z), Amoxicillin (AM), Rocephin (R), Ciprofloxacin (CPX), Streptomycin (S), Septrin (SXT), and Erythromycin (E)

associated with gas gangrene which is highly fatal and may result into death in less than $24 \mathrm{~h}$ (Katlic, 1980). Clostridium septicum is highly pathogenic in immune-compromised individuals, Corynebacterium striatum have been implicated in endocarditis, bacteremia and catheter infections (Coyle et al., 1990). Bacillus cereus causes food poisoning, diarrhea, severe nausea and vomiting (McKillip, 2000). Bacillus circulans is a pathogen incriminated in human infection such as septicemia, mixed abscesses and wound infection. Antibiotic resistance increases in the environment as they replicate their genetic materials; this means that resistance can spread from one species of bacteria to the other enabling it to develop multiple resistances to different classes of antibiotics. Electromagnetic fields have been reported in acquisition of resistance to Cephalosporins (Cefuroxime and Ceftazidime) (Fojt et al., 2007; Cellini et al., 2008). Justo et al. (2006) reported that cell growth could be altered (stimulated or inhibited) under magnetic field effects. Exposure of bacteria to radiation have been reported to cause changes in the growth characteristic, morphology, structural properties of proteins, and the sensitivity and resistance to certain antibiotics such as amoxicillin, nalidixic acid, and erythromycin (Gaafar et al., 2006; Gaafar et al., 2008). These results were in agreement with the work of Stansell et al. (2001) who found that moderate intensity static fields were able affect antibiotic sensitivity and resistance of bacteria. Furthermore, Belyaev (2011) showed that RFR, under specific conditions of exposure (frequency ranging from $8.5 \mathrm{~Hz}$ to $9 \mathrm{~Hz} ; 0.021 \mathrm{mT}$ ), acted as a nontoxic but cell-growth stimulating agent on E. coli GE499. Again, the exposure of E. coli HB101 to radiation produced a stimulation of cell growth (Babushkina et al., 2005). By contrast, Grosman et al. (1992) found that static magnetic fields ranging from 0.5 to $4.0 \mathrm{~T}$ had no significant influence on the growth rate and antibiotic sensitivity of E. coli and Staphylococcus aureus. A direct comparison of these studies with results obtained in this work may be difficult because of the dissimilar experimental procedures employed. It is well known that the effects of radiation generally depend on both physical and biological parameters, including field signal characteristics (frequency, amplitude, wave shape, etc.), duration of exposure, cell metabolic state, genotype, and how long cells are allowed to grow before, during, and after exposure.

This work which aimed to investigate the effects of Radiofrequency radiation from telecommunication base stations on bacteria diversity and antibiotic resistance of surrounding bacteria micro-flora have shown that radiation influences and selected bacteria of specific morphology (rod-like and gram positive), imposes stress detrimental to various non-spore forming, gram negative bacteria of non-rod morphology and possibly may contribute to antibiotic resistance. Further research in this area is advised with the possibility of development of necessary hazard control measures for the protection of the environment from outbreak of antibiotic resistant organisms.

\section{E.A, ADEBAYO ${ }^{1}$; A.O, ADEEYO ${ }^{1}$; A.A, AYANDELE ${ }^{1}$;.O, OMOMOWO}




\section{REFERENCES}

Adebayo E A; Majolagbe O N; Ola I O and Ogundiran M A (2012). Antibiotic resistance pattern of isolated bacteria from salads. Journal of Research in Biology. 2: 136-142.

Babushkina I V; Borodulin V B; Shmetkova N A (2005).The influence of alternating magnetic field on Escherichia coli bacterial cells. Pharmaceutical Chemistry Journal. 39: 398400.

Belyaev I (2005). Non-thermal biological effects of microwaves. Microw. Rev. 11: 13-29

Belyaev I (2011). Toxicity and SOS-response to ELF magnetic fields and nalidixic acid in $E$. coli cells. Mutation Research. 722: 56-61.

Buchanan R E and Gibbons N E (1974). Bergeys Manual of Determinative Microbiology, $8^{\text {th }}$ edition. The Williams and Wilkins Co, Baltimore, Md.

Bush K; Courvalin P; Dantas G (2011).Tackling antibiotic resistance. Nature Reviews Microbiology. 9:894-896.

Cellini L; Grande R; Di-Campli E (2008). Bacterial response to the exposure of $50 \mathrm{~Hz}$ electromagnetic fields. Bioelectromagnetics. 29: 302-311.

CLSI (2007). Performance Standard for Antimicrobial Susceptibilty Testing: $17^{\text {th }}$ informational supplement, M100-S17; 27(1), Clinical and Laboratory Standard Institute, Wayne, Pa, USA.

Conner-Kerr T A, Sullivan P K, Gaillard J and Jones R M (1998) The effects of ultraviolet radiation on antibiotic resistant bacteria In Vitro. Ostomy/Wound Management. 44:50-56

Coyle M B and Lipsky B A (1990). Coryneform bacteria in infectious diseases: clinical and laboratory aspects. Clin. Microbiol. Rev. 3: 227 246

De-mattei M; Varani K; Masieri F F (2009). Adenosine analogs and electromagnetic fields inhibit prostaglandin E2 release in bovine synovial fibroblasts. Osteoarthritis and Cartilage. 17: 252-262.
Di-Loreto S; Falone S; Caracciolo V (2009). Fifty hertz extremely low-frequency magnetic field exposure elicits redox and trophic response in rat-cortical neurons. Journal of Cellular Physiology. 219:334-343.

Firstenberg A (1997). Microwaving Our Planet: The Environmental Impact of the Wireless Revolution, Cellular Phone Taskforce, Brooklyn, NY.

Fojt L; Klapetek P; Stra`s'ak L and Vetterl V (2009). $50 \mathrm{~Hz}$ magnetic field effect on the morphology of bacteria. Micron. 40: 918-922.

Fojt L; Stra`s'ak L; Vetterl V and 'Smarda J (2004). Comparison of the low-frequency magnetic field effects on bacteria Escherichia coli, Leclercia adecarboxylata and Staphylococcus aureus. Bioelectrochemistry. 63: 337-341.

Foletti A; Lisi A; Ledda M; De-Carlo F and Grimaldi S (2009). Cellular ELF signals as a possible tool in informative medicine. Electromagnetic Biology and Medicine. 28;71-79.

Gaafar E S A; Hanafy M S; Tohamy E T and Ibrahim M H (2006). Stimulation and control of $E$. coli by using an extremely low frequency magnetic field, Romanian Journal of Biophysics. 16: 283-296.

Gaafar E S A; Hanafy M S; Tohamy E T and Ibrahim M H (2008). The effect of electromagnetic field on protein molecular structure of $E$. coli and its pathogenesis. Romanian Journal of Biophysics. 18:145-169,

Galeev A L (2000). The effects of microwave radiation from mobile telephones on humans and animals, Neurosci. Behav. Physiol. 30: 187-194

Giorgi G; Marcantonio P; Bersani F; Gavoci E; and Del-Re B (2011). Effect of extremely low frequency magnetic field exposure on DNA transposition in relation to frequency, wave shape and exposure time. International Journal of Radiation Biology. 87: 601-608.

Goodman R; Lin-Ye A; Geddis M S (2009). Extremely low frequency electromagnetic fields activate the ERK cascade, increase hsp70 protein levels and promote regeneration in Planaria. International Journal of Radiation Biology. 85: 851-859. 
Grassi C; D’Ascenzo M; Torsello A (2004). Effects of $50 \mathrm{~Hz}$ electromagnetic fields on voltage-gated $\mathrm{Ca} 2+$ channels and their role in modulation of neuroendocrine cell proliferation and death. Cell Calcium. 35: 307-315.

Huang L; Dong L; Chen Y; Qi H and Xiao D (2006). Effects of sinusoidal magnetic field observed on cell proliferation, ion concentration, and osmolarity in two human cancer cell lines. Electromagnetic Biology and Medicine. 25: 113126.

Rifat H; Safdar A; Ummay A and Rabia K; Iftikhar A (2010). Soil beneficial bacteria and their role in plant growth promotion: a review. Ann Microbiol. DOI 10.1007/s13213-010-0117-1

Inhan-Garip A; Aksu B; Akan Z; Akakin D; Ozaydin A N and San T (2011). Effect of extremely low frequency electromagnetic fields on growth rate and morphology of bacteria. International Journal of Radiation Biology. 87:1155-1161.

Iorio R; Delle-Monache S; Bennato F (2011). Involvement of mitochondrial activity in mediating ELF-EMF stimulatory effect on human sperm motility. Bioelectromagnetics. 32: $15-27$.

Jia F; Ushiyama A; Masuda H; Lawlor G F and Ohkubo C (2007). Role of blood flow on RF exposure induced skin temperature elevations in rabbit ears. Bioelectromagnetics. 28:163-172.

Justo O R; Perez V H; Alvarez D C and Alegre R M (2006). Growth of Escherichia coli under extremely low-frequency electromagnetic fields. Applied Biochemistry and Biotechnology. 134: 55-163.

Katlic M R; Derkac W M and Coleman W S (1980). Clostridium septicum infection and Malignancy. Ann. Surg. 193: 362-364

Ke X Q; Sun W J; Lu D Q; Fu Y T and Chiang H (2008). $50 \mathrm{~Hz}$ magnetic field induces EGFreceptor clustering and activates RAS. International Journal of Radiation Biology. 84: 413-420.Levy S B (2001). Antibiotic resistance: nsequences of inaction. Clinical Infectious Diseases.33:124-129
Lisi A; Ledda M; De-Carlo F (2008). Calcium ion cyclotron resonance (ICR) transfers information to living systems: effects on human epithelial cell differentiation. Electromagnetic Biology and Medicine. 27: 230-240.

Lisi A; Ledda M; Rosola E (2006). Extremely low frequency electromagnetic field exposure promotes differentiation of pituitary corticotrope-derived AtT20 D16V cells. Bioelectromagnetics. 27: 641-651.

McKillip J L (2000). Prevalence and expression of enterotoxins in Bacillus cereus and other Bacillus species: a literature review. Antonie Van Leeuwenhoek. 77: 393-399

Piacentini R; Ripoli C; Mezzogori D; Azzena G B and Grassi C (2008). Extremely low-frequency electromagnetic fields promote in vitro neurogenesis via upregulation of Cav1- channel activity. Journal of Cellular Physiology. 215:129-139.

Schwartz Z; Simon B J; Duran M A; Barabino G; Chaudhri R and Boyan B D (2008). Pulsed electromagnetic fields enhance BMP-2 dependent osteoblastic differentiation of human mesenchymal stem cells. Journal of Orthopaedic Research. 26: 1250-1255.

Simk'M (2007). Cell type specific redox status is responsible for diverse electromagnetic field effects. Current Medicinal Chemistry. 14:11411152.

Stra`s'ak L; Vetterl V and Smarda J (2002). Effects of low-frequency magnetic fields on bacteria Escherichia coli. Bioelectrochemistry. 55: 161164.

Vianale G; Reale M; Amerio P; Stefanachi M; DiLuzio S and Muraro R (2008). Extremely low frequency electromagnetic field enhances human keratinocyte cell growth and decreases proinflammatory chemokine production. British Journal of Dermatology. 158:1189-1196. 